\title{
Total T4 rise in pregnancy: a relook?
}

\author{
Subhodip Pramanik, Pradip Mukhopadhyay and Sujoy Ghosh *i]
}

\begin{abstract}
Background: Total T4 (TT4) measurement is preferred to free T4 (FT4) especially in last part of pregnancy. Guidelines by American Thyroid Association, European Thyroid Association and Endocrine Society state that TT4 increases 1.5 times pre-pregnant levels after week 16 of pregnancy. However, this is based on a small study conducted 40 years ago which used radioimmunoassay for determination in changes in TT4.

Materials and methods: A cross-sectional study was undertaken to find reference interval for thyroid function in different trimester of pregnancy with special reference to look at the degree of elevation of TT4 as compared to non-pregnant women. Two hundred non-pregnant women (excluding oral contraceptive users) and 600 pregnant women (200 from each trimester) aged 18-40 years were consecutively recruited starting from around 6th week of pregnancy having confirmed singleton pregnancy diagnosed at 8th week by ultrasound. The exclusion criteria included: (1) a personal or family history of thyroid disease; (2) presence of goiter or nodule confirmed by ultrasound; (3) anti-TPO antibody positive state (titre $>35 \mathrm{IU} / \mathrm{ml}$ ). All subjects were tested for urinary spot iodine concentration and those with UIC $<150 \mu \mathrm{g} / \mathrm{L}$ were excluded. Finally, thyroid function tests (TSH, FT4, TT4, TT3) of 168 non-pregnant women and 163, 153 and 148 women at 1st, 2nd and 3rd trimester respectively were analysed..

Results: Total T4 (mean \pm SD, $\mu \mathrm{g} / \mathrm{dl}$ ) in non pregnant women and in different trimesters was $8.95 \pm 1.71,9.71 \pm 2.39$, $12.11 \pm 1.55,11.83 \pm 1.49$ respectively. Rise in $T 4$ occurred between 10-18th week. The mean TT4 in second trimester increased by $25 \%$ as compared with the value at 6-9th week and by $35 \%$ as compared to non-pregnant value.

Conclusion: Rise in total T4 in second trimester pregnancy is only around $25 \%$ as compared to first trimester value and 35\% than the non-pregnant value. Hence multiplying non-pregnant T4 value by 1.5 may actually over-diagnose maternal hypothroxinemia and lead to inappropriate diagnosis and treatment of isolated maternal hypothyroxinemia in a significant proportion of subjects.
\end{abstract}

Keywords: Thyroid function tests, Pregnancy, Reference range, Total T4

\section{Background}

Non-pregnant cut-offs for thyroid function do not appropriately reflect thyroid status during pregnancy. Current guideline suggests, instead of measuring FT4 (free T4), measurement of TT4 (total T4) (with a pregnancy-adjusted reference range) is a highly reliable means of estimating hormone levels during last part of pregnancy [1]. FT4 assay during pregnancy is highly

\footnotetext{
* Correspondence: drsujoyghosh2000@gmail.com

Department of Endocrinology and Metabolism, I.P.G.M.E\&R, Kolkata, West Bengal 700020, India
}

(c) The Author(s). 2020 Open Access This article is licensed under a Creative Commons Attribution 4.0 International License, which permits use, sharing, adaptation, distribution and reproduction in any medium or format, as long as you give appropriate credit to the original author(s) and the source, provide a link to the Creative Commons licence, and indicate if changes were made. The images or other third party material in this article are included in the article's Creative Commons licence, unless indicated otherwise in a credit line to the material. If material is not included in the article's Creative Commons licence and your intended use is not permitted by statutory regulation or exceeds the permitted use, you will need to obtain permission directly from the copyright holder. To view a copy of this licence, visit http://creativecommons.org/licenses/by/4.0/. The Creative Commons Public Domain Dedication waiver (http://creativecommons.org/publicdomain/zero/1.0/) applies to the data made available in this article, unless otherwise stated in a credit line to the data.

variable and depends on assay method and age of gestation $[1,2]$. Koevaar et al. suggested that maternal TT4 levels, especially in first half of pregnancy are either not associated or not better associated as compared to FT4, with adverse pregnancy or child outcomes [3].

American Thyroid Association, European Thyroid Association and Endocrine Society suggests that we use TT4 during pregnancy to diagnose hypothyroxinaemia and normative reference ranges in pregnancy for TT4 is determined by multiplying the non-pregnant value by 1.5 in second and third trimester $[1,4,5]$. Total T3 and T4 starts to increase gradually and peaks by 16 th week 
of pregnancy and the magnitude of increase is stated to be upto $50 \%$ of that at the start of pregnancy. If a T4 measurement is required in the early part of pregnancy (i.e., weeks $7-16$ of pregnancy), it is suggested that we can estimate an upper reference range based on increasing the non-pregnant upper reference limit by $5 \%$ per week (starting from 7th week of gestation). The assumption that there is a $50 \%$ rise in $\mathrm{T} 4$ is based on a study by Weeke $\mathrm{J}$ et al. which documented that $\mathrm{T} 3$ and $\mathrm{T} 4$ are approximately 1.5 times of the values measured 10 weeks post-partum [6]. However this study was conducted in 1982 and the values were documented longitudinally from the same cohort of women upto 12 wks after delivery. The study had several limitations, namely, small sample size (only 20), subjects were not evaluated for possible underlying subtle thyroid diseases (including presence/absence of goiter, autoimmunity). Additionally iodine status was not evaluated and an older generation of radioimmunoassay was used. In this study it is assumed that thyroid function test at 12 weeks postpartum is representative of pre-pregnant values. This assumption may be fallacious due to high prevalence of postpartum thyroiditis (upto $22 \%$ in some studies) [7].

In the study by Zhang et al., when the lower limit of non-pregnant TT4 is multiplied by a factor of 1.5; it was found that almost $29.3 \%$ of subjects in first trimester of pregnancy would fulfil the diagnostic criterion of hypothyroxinemia [8]. This obviously would overdiagnose hypothyroidism in pregnancy as compared to other studies [9] and possibly result in inappropriate levothyroxine therapy in a significant proportion of pregnant women. Korevaar et al. also demonstrated that the change of mean maternal TT4 levels was $27.5 \%$ higher at 18th week of pregnancy as compared to 8th week [3].

Considering all of the aforementioned limitations and conflicting data and with availability of newer assay methods, it is imperative to have a relook at the quantum of change of T4 during pregnancy.

\section{Main text}

We undertook a cross-sectional study to establish reference interval/normative data for thyroid function tests in an Indian population with special reference to determine the quantum of change of total T4 during pregnancy as compared to non-pregnant women. The preliminary data of the on-going study has been published [10]. The data presented herein is an extension of the said study with inclusion of more subjects.

Two hundred non-pregnant women (excluding oral contraceptive users) and 600 pregnant women (200 from each trimester) aged 18-40 years were consecutively recruited starting from around 6th week of pregnancy having confirmed singleton pregnancy diagnosed at 8th week by ultrasound. The exclusion criteria included: (1) a personal or family history of thyroid disease; (2) presence of goiter or nodule confirmed by ultrasound; (3) anti-TPO antibody positive state (titre $>35 \mathrm{IU} / \mathrm{ml}$ ). All subjects were tested for urinary spot iodine concentration and those with UIC (Urinary Iodine Concentration) $<150 \mu \mathrm{g} / \mathrm{L}$ were excluded. After exclusion, the number

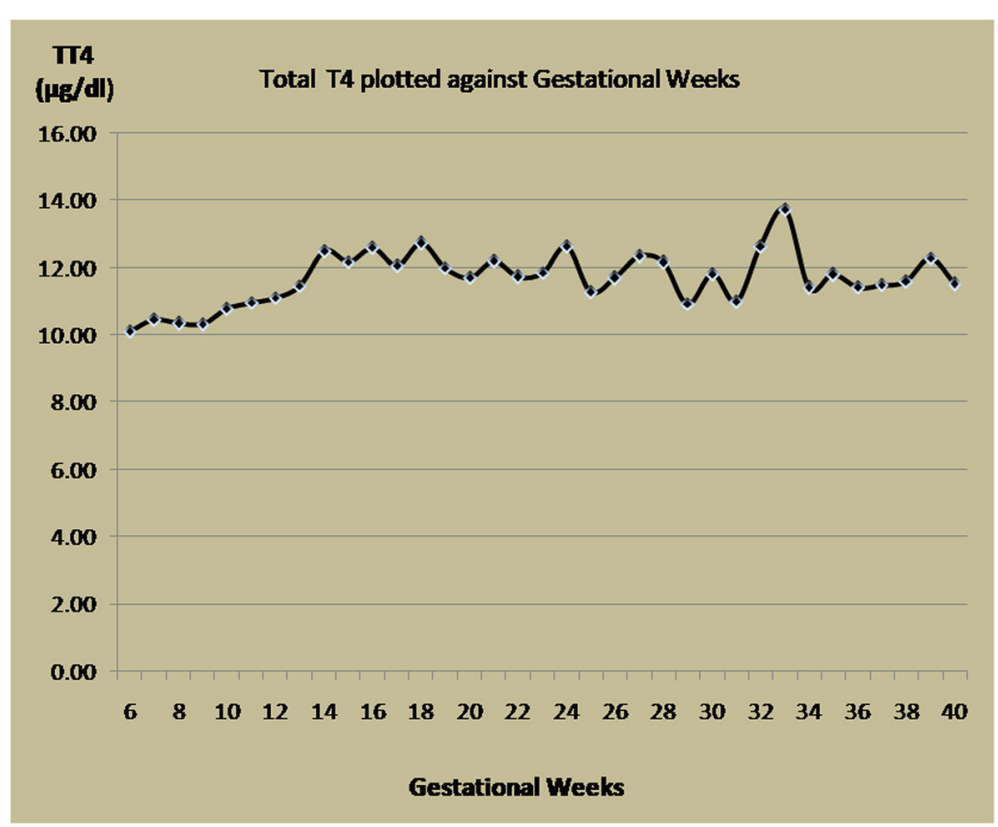

Fig. 1 Total T4 plotted against gestational weeks 
of subjects eligible in 1st, 2nd, 3rd trimesters and non pregnant group was 163, 153, 148 and 168 respectively.

TT4 was estimated by Chemiluminescence technique (CLIA) using commercially available kits from Siemens Diagnostics (Germany) with Immulite-1000 analyzer. The analytical sensitivity was $0.4 \mu \mathrm{g} / \mathrm{dl}$. The laboratory reference ranges was $4.5-12 \mu \mathrm{g} / \mathrm{dl}$ and the inter-assay coefficients of variation (CV) was $6.7 \%$.

Total T4 (mean $\pm \mathrm{SD}, \mu \mathrm{g} / \mathrm{dl})$ in non-pregnant women and in different trimester was $8.95 \pm 1.71,9.71 \pm 2.39$, $12.11 \pm 1.55,11.83 \pm 1.49$ respectively. TT4 increased from around 10-12 week to reach a peak around 18th weeks, after which it almost plateaued. The increment at $10-18$ weeks is approximately $25 \%(24.71 \%)$ as compared to 1 st trimester values (Fig. 1). Compared to the nonpregnant women, the increment in TT4 is approximately $35 \%$ (35.30\%).

Zhang et al. compared the relationship between selfsequential longitudinal levels of thyroid hormones with cross-sectional levels, while investigating the reference range of thyroid function during pregnancy [8]. They established that there is no significant difference between a self-sequential longitudinal reference interval and a cross-sectional reference interval [8]. Hence we used a cross-sectional reference interval in our analysis for convenience. In most situations, pre-pregnancy thyroid function test reports are not available. Hence we tried to document the degree of elevation of TT4 with respect to first trimester value also. A possible limitation of the study is that we evaluated anti-TPO antibody, but did not check anti-thyroglobulin antibody.

The finding of maximum increment in TT4 by 35\% with respect to the non-pregnant women is in clear contrast with the traditional wisdom that TT4 rises maximally upto $50 \%$ of the non pregnant value after week 16 of pregnancy [1]. This finding has significant clinical implications and should be validated in larger cohort and in other ethnic groups.

\section{Conclusion}

We conclude that the rise of TT4 peaks between 10-18th week of gestation and mean TT4 during second trimester is increased by $25 \%$ as compared with 6-9th week and by $35 \%$ as compared to non-pregnant value which is much less than what current guidelines suggest. This we believe would lead to avoidance of inappropriate diagnosis and treatment of isolated maternal hypothyroxinemia in a significant proportion of subjects. This finding also reinforces the necessity of establishing trimester-specific hormone ranges to diagnose thyroid dysfunction during pregnancy.

\section{Abbreviations}

TT4: Total T4; FT4: Free T4; UIC: Urinary lodine Concentration; TPO: Thyroid peroxidase

\section{Acknowledgements}

We sincerely acknowledge Endocrine Society of Bengal, Kolkata, India for financial support to conduct the study.

\section{Authors' contributions}

Conceptualization of the Study and manuscript editing: SG. Patient Selection and Conduct of test: SP, Data Analysis and manuscript Preparation: PM. The author(s) read and approved the final manuscript

\section{Funding}

Endocrine Society of Bengal, Kolkata, India. Vide Grant No: IPGMER/Endo/11/2017.

Availability of data and materials

Available

Ethics approval and consent to participate

All research protocols were approved by the Institutional Ethics Committee of Institute of Post Graduate Medical Education and Research and SSKM Hospital, Kolkata, India and were congruent with the declaration of Helsinki. Informed consent was obtained from all subjects.

\section{Consent for publication}

All authors give consent for publication.

\section{Competing interests}

None declared.

Received: 30 March 2020 Accepted: 20 July 2020

Published online: 31 July 2020

\section{References}

1. Alexander EK, Pearce EN, Brent GA, Brown RS, Chen H, Dosiou C, et al. 2017 guidelines of the American Thyroid Association for the diagnosis and management of thyroid disease during pregnancy and the postpartum. Thyroid. 2017;27(3):315-89.

2. Lee RH, Spencer CA, Mestman JH, Miller EA, Petrovic I, Braverman LE, Goodwin TM. Free T4 immunoassays are flawed during pregnancy. Am J Obstet Gynecol. 2009;200(3):260.e1-6. https://doi.org/10.1016/j.ajog.2008.10.042.

3. Korevaar T, Chaker L, Medici M, de Rijke YB, Jaddoe WW, Steegers EA, et al. Maternal total T4 during the first half of pregnancy: physiologic aspects and the risk of adverse outcomes in comparison with free T4. Clin Endocrinol. 2016;85(5):757-63. https://doi.org/10.1111/cen.13106

4. Lazarus J, Brown RS, Daumerie C, Hubalewska-Dydejczyk A, Negro R, Vaidya B. 2014 European thyroid association guidelines for the Management of Subclinical Hypothyroidism in pregnancy and in children. Eur Thyroid J. 2014;3(2):76-94.

5. De Groot L, Abalovich M, Alexander EK, Amino N, Barbour L, Cobin RH, et al. Management of thyroid dysfunction during pregnancy and postpartum: an Endocrine Society clinical practice guideline. J Clin Endocrinol Metab. 2012; 97:2543-65.

6. Weeke J, Dybkjaer L, Granlie K, Eskjaer Jensen S, Kjaerulff E, Laurberg P, Magnusson B. A longitudinal study of serum TSH and total and free iodothyronines during normal pregnancy. Acta Endocrinol. 1982;101(4):531-7.

7. Di Bari F, Granese R, Le Donne M, Vita R, Benvenga S. Autoimmune Abnormalities of Postpartum Thyroid Diseases. Front Endocrinol. 2017;13(8):166.

8. Zhang X, Yao B, Li C, Mao J, Wang W, Xie X, Teng X, Han C, Zhou W, Li C, $\mathrm{Xu} B$. Reference intervals of thyroid function during pregnancy: selfsequential longitudinal study versus cross-sectional study. Thyroid. 2016; 26(12):1786-93.

9. Henrichs J, Bongers-Schokking JJ, Schenk JJ, Ghassabian A, Schmidt HG, Visser TJ, et al. Maternal thyroid function during early pregnancy and cognitive functioning in early childhood: the generation R study. J Clin Endocrinol Metab. 2010;95(9):4227-34

10. Pramanik S, Mukhopadhyay P, Bhattacharjee K, Bhattacharjee R, Mukherjee $B$, Mondal SA, et al. Trimester-specific reference intervals for thyroid function parameters in Indian pregnant women during final phase of transition to iodine sufficiency. Indian J Endocr Metab. 2020;24:160-4.

\section{Publisher's Note}

Springer Nature remains neutral with regard to jurisdictional claims in published maps and institutional affiliations. 